\title{
Simulation and Analysis of Small Break LOCA for AP1000 Using RELAP5-MV and Its Comparison with NOTRUMP Code
}

\author{
Eltayeb Yousif, Zhijian Zhang, Zhaofei Tian, and Hao-ran Ju \\ College of Nuclear Science and Technology, Harbin Engineering University, 145 Nantong Street, Harbin, Heilongjiang 150001, China \\ Correspondence should be addressed to Zhaofei Tian; tian_zf@hrbeu.edu.cn
}

Received 19 December 2016; Revised 15 February 2017; Accepted 23 March 2017; Published 19 June 2017

Academic Editor: Borut Mavko

Copyright (c) 2017 Eltayeb Yousif et al. This is an open access article distributed under the Creative Commons Attribution License, which permits unrestricted use, distribution, and reproduction in any medium, provided the original work is properly cited.

\begin{abstract}
Many reactor safety simulation codes for nuclear power plants (NPPs) have been developed. However, it is very important to evaluate these codes by testing different accident scenarios in actual plant conditions. In reactor analysis, small break loss of coolant accident (SBLOCA) is an important safety issue. RELAP5-MV Visualized Modularization software is recognized as one of the best estimate transient simulation programs of light water reactors (LWR). RELAP5-MV has new options for improved modeling methods and interactive graphics display. Though the same models incorporated in RELAP5/MOD 4.0 are in RELAP5$\mathrm{MV}$, the significant difference of the latter is the interface for preparing the input deck. In this paper, RELAP5-MV is applied for the transient analysis of the primary system variation of thermal hydraulics parameters in primary loop under SBLOCA in AP1000 NPP. The upper limit of SBLOCA (10 inches) is simulated in the cold leg of the reactor and the calculations performed up to a transient time of 450,000.0 s. The results obtained from RELAP5-MV are in good agreement with those of NOTRUMP code obtained by Westinghouse when compared under the same conditions. It can be easily inferred that RELAP5-MV, in a similar manner to RELAP5/MOD4.0, is suitable for simulating a SBLOCA scenario.
\end{abstract}

\section{Introduction}

The AP1000 is an advanced NPP. The AP1000 core has fourteen- (14-) foot active fuel length, rated for a thermal power of $3400 \mathrm{MWt}$ and net electrical power of at least 1117 MWe. The core of AP1000 has two loops in the reactor cooling system (RCS). Each loop comprises one hot leg and two cold legs. One of the innovative designs of the AP1000 is based on a simple principle for design-basis accident; like main coolant-pipe rupture, the reactor is designed to attain a safe shutdown condition without operator intervention and without the use of AC power or pumps. The AP1000 plant has a multilayer level of protection against accident (defensein-depth), which gives it a low probability of core damage. The possibilities of containment flooding, pressurization, and overheating are drastically reduced. The reactor also has a robust control system and novel design that provide substantial margins for plant operation before approaching failure thresholds. As a result of the AP1000 reactor's passive safety systems, the need for operator intervention to prevent accident is not necessary. The passive safety systems operate based on physical principles which rarely fail, all things being equal. Due to the fact that the reactor uses less active systems such as fans, pumps, chillers, or other active machinery, the reactor is therefore less prone to accident. The AP1000 reactor's passive systems include passive core cooling system (PXS), in-containment refueling water storage tank (IRWST), passive containment cooling system (PCS), main control room emergency habitability system, high pressure safety injection with core makeup tanks (CMTs), medium pressure safety injection with accumulators, low pressure reactor coolant make from the IRWST, passive residual heat removal (PRHR HX), and automatic depressurization system (ADS) shown in Figure 1 $[1,2]$.

In the AP1000 reactor, the three main sources of water provided for cooling the reactor core and decay (residual) heat removal to avoid core uncover is in-containment refueling water storage tank (IRWST), core makeup tank (CMT), and the accumulators systems [3].

The two CMTs are slightly raised above the reactor core. The discharge injection line and an inlet pressure balance line connect the CMTs to the RCS. The top of CMT is 


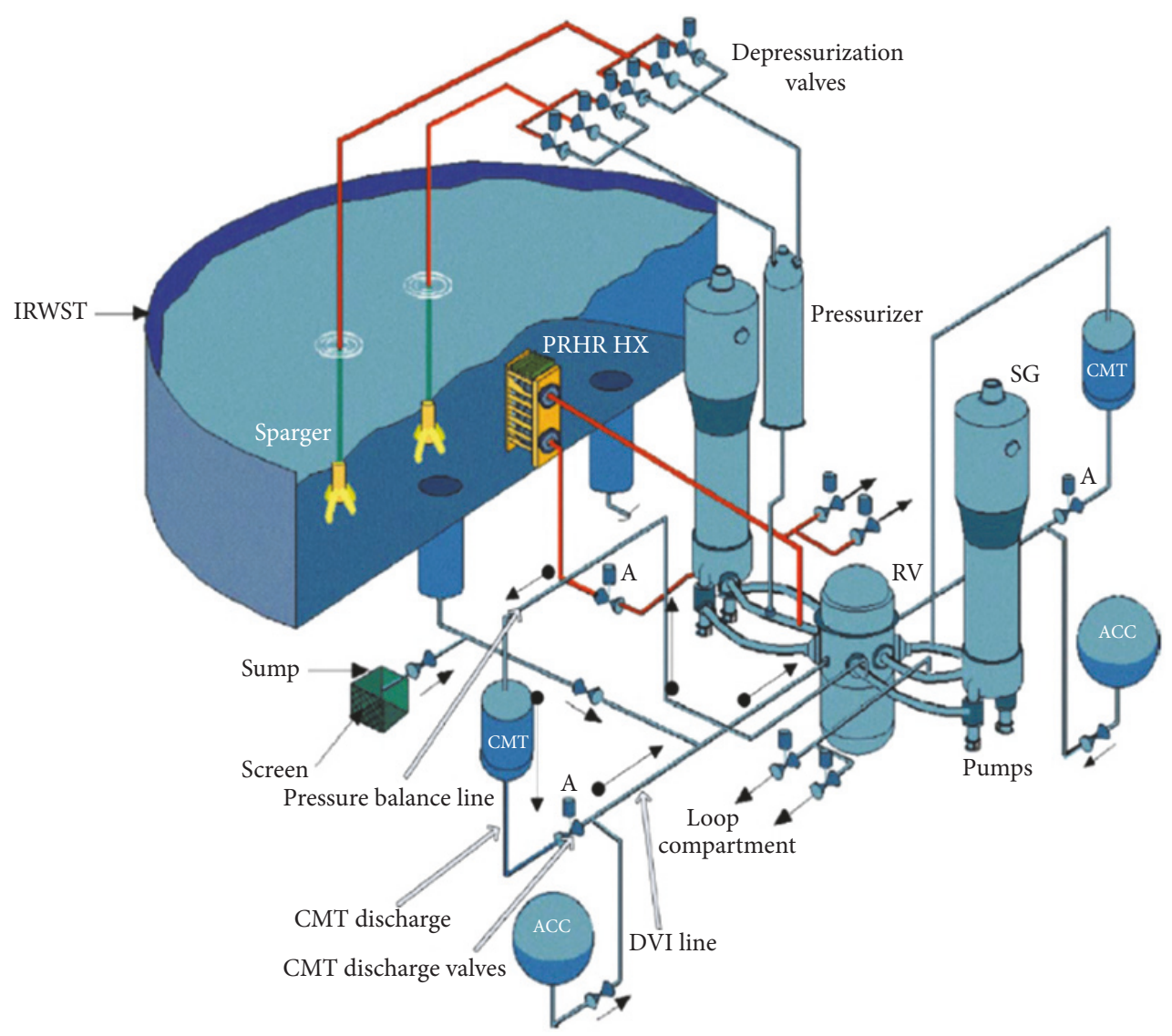

FIGURE 1: AP1000 passive core cooling system.

connected with the cold leg to maintain the CMT pressure equal to the primary system pressure. The outlet or bottom part of CMT is connected with DVI line through discharge line. There are two parallel air operated valves on CMT discharge line which are normally open and isolate CMT discharge to DVI line [4]. The main features of the passive safety system can be divided into the passive containment cooling system (PCS) with its provider of emergency ultimate heat sink being the atmosphere and passive core cooling system (PXS). The PXS is divided into three parts which are the PRHRS, PSIS, and ADS. The PRHRS, PSIS, and ADS perform the functions of decay heat removal from the reactor core, safety injection cooling, and reactor cooling system depressurization, respectively. The passive core cooling system is located inside the containment, and it is dependent on subequipment and linked components [5]. One of the subsystems is the passive residual heat removal heat exchanger (PRHR HX). The PRHR HX consists of Cshaped tubes used to remove decay heat from reactor core system during transient or accident situations when there is a loss of cooling. And it is designed to operate based on only natural forces such as gravity and natural circulation $[6,7]$. The PRHR HX located inside the in-containment refueling water storage tank (IRWST) is the major component responsible for heat removal and is shown in Figure 2.
As shown in Figure 3. The passive safety injection system (PSIS) is employed to removal decay heat from the reactor core cooling system in cases of accident. It consists of two pressurized accumulators (ACCs) which provide a very high flow borated water in a short time after system pressure drops for a limited duration; two core makeup tanks (CMTs) which are involved in high pressure safety injection; in-containment refueling water storage tank (IRSWT) which provides a low pressure reactor coolant and lower flow but for a much longer time after pressure decreases to close the pressure of containment and provides an additional source of water for long-term core cooling $[5,9,10]$.

The design of AP1000 ADS consists of 4-stage depressurization valves that are opened sequentially to provide controlled depressurization of the primary system during a SB-LOCA process. The ADS consists of two trains of 4stage valves. The ADS-1, ADS-2, and ADS-3 are connected to the pressurizer steam space and the ADS- 4 is connected to the hot legs. The effect of SBLOCA is reduced through the sequential depressurization of ADS which allows passive injection from the CMTs, the accumulators, and the IRWST [5].

RELAP5 plays an important role in the evaluation of NPPs for various planned and accident conditions. It is also one of the best estimate programs for LWR transient hydraulic and thermal analysis code. 


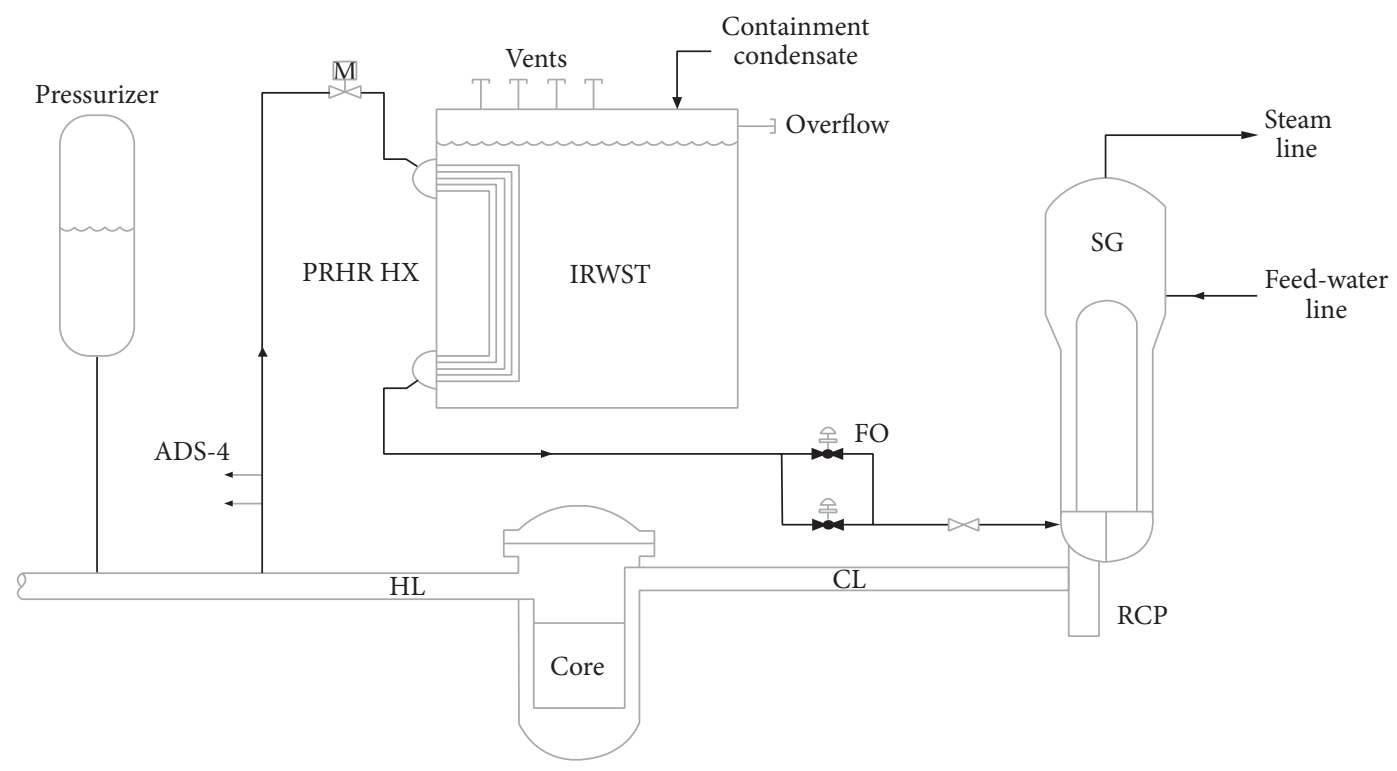

Figure 2: Passive residual heat removal system [5].

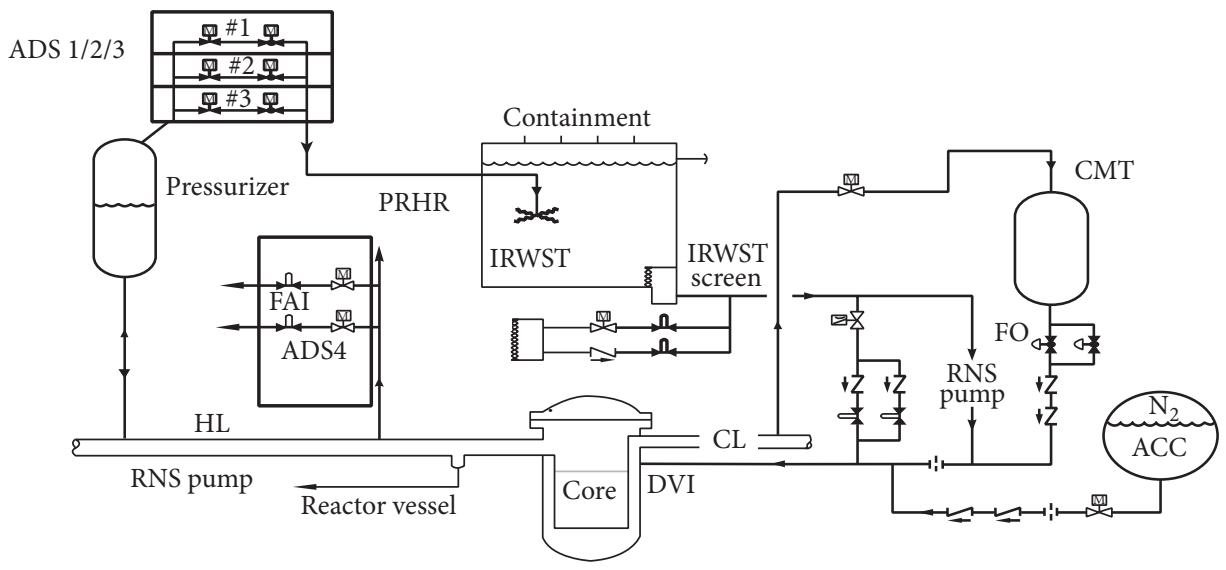

FIgURE 3: Passive safety injection system [8].

Nowadays, majority of the software applications have developed graphical user interface (GUI) in addition. With GUI, the user is able to learn, understand, and use the application software with ease especially the beginners. GUIs developed for visualization of the results in the safety analysis of nuclear related facilities are purposely for computational fluid dynamic codes, system codes, and severe accident codes amongst others. The RELAP5 code has been made to be more interactive and user friendly through some developed GUIs. As expected, these GUIs have their models based on RELAP5.

Some of these user aids and interfaces have been categorized into three which are the input model builders, transient aids, and postprocessors. Input aids make the development of an input deck for RELAP5 easy. Some of the prominent input aids are PYGMALION [11], ATHENAAide [12], TROPIC [13], and SNAP [14] amongst others. The transient aids such as NPA [15] and RELSIM [16] present the results graphically and enable the user to interact with the status of the computations. Finally, the postprocessors, XMGR5 [17], NPA, and PYGMALION [18, 19], collate and present the calculations already completed. A detailed listing of most GUIs and the developed user aid are collated in different surveys. Specifically, the development of RGUI is presented in detail in $[15,18-20]$.

Few decades ago, the United States Nuclear Regulatory Commission (NRC) mandated the development of GUIs for all their developed software applications of which RELAP5 code is inclusive. In 1996, Nuclear Plant Analyzer (NPA) happened to be the foremost of those developed GUI [21]. It laid emphasis on visualizing reactor coolant behaviors during a simulated transient.

Based on the way SNAP [22] was designed, safety analysis has been greatly simplified. It is mainly for creating and editing inputs for safety analysis codes and suitable for code coupling. SNAP easily supports many codes like the CONTAIN [23], COBRA, FRAPCON-3, MELCOR, PARCS, 
RELAP5 [24], and TRACE [25]. Each code is supported by different plug-ins. The SNAP interactive and postprocessing capabilities are possible through its animation displays.

Aside SNAP, the RELSIM, is also an advanced interactive simulator GUI. RELSIM is a commercially available package being developed by Risk Management Associates (RMA). The combined package, RELSIM-RELAP/SCDAPSIM, is being used for research and training purposes in institutions of learning and research centres. It also helps other novice reactor systems analysts to understand the complexity of thermal hydraulic and/or reactor systems performance under realistic and postulated conditions.

RELAP/SCDAPSIM uses developed and validated system thermal hydraulic, fuel behavior, and severe accident models by researchers worldwide. This is in combination with a flexible building block approach to model thermal hydraulic and reactor systems. In the same manner, RELSIM uses a building block approach and user defined graphics screens in combination with the ability to interactively control the RELAP/SCDAPSIM simulation [26].

In this paper, RELAP5-MV Visualized Modularization software is presented as one of the best estimate transient simulation programs of LWR with new options for improved modeling and integrated graphics displays. The software has been applied for simulation and analysis of a SBLOCA in one of the cold legs in nonpressurized side of the primary loop of AP1000, with 10-inch break size. It is a very convenient and suitable software for predicting the plant behavior. It is characterized by a user friendly computer interface for building system models.

\section{RELAP5-MV}

RELAP5 is developed by Idaho National Engineering and Environmental Laboratory (INL) [27].

Since its debut in 1985, when the first RELAP5/MOD2 was introduced, many changes have been made to make the code more realistic and user friendly, with large range of analytical capability [28] since it was difficult to simulate complex phenomena with the old version of code. There are some challenges when using RELAP5, some of these are briefly discussed below. First of all, too many components make it hard and complex for beginners to understand and make use of RELAP5 due to over ten (10) categories of input cards with dozens of components. Then editing input cards by notepad, too many data with complex logic relationship makes up the input file, which makes it quite hard to modify and seek specific parameters. Due to lack of visualization, searching input file for information of equipment becomes a complicated task.

A RELAP5 problem input deck consists of at least one title card, optional comment cards, data cards, and a terminator card. A list of these input cards is printed at the beginning of each RELAP5 problem. For parameter studies and for temporary changes, a new title card with the inserted, modified, and deleted data cards and identifying comment cards should be placed just ahead of the terminating card [29].

Finally, the complex process of modeling and debugging of the code is time-consuming and decreases productivity. An

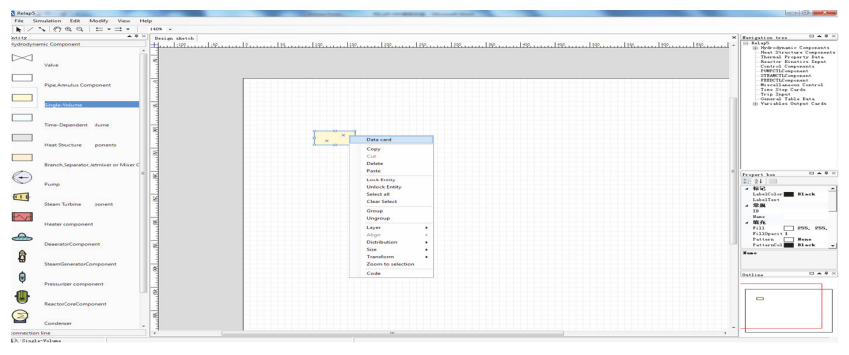

FIGURE 4: Single volume input display.

attempt to solve these disadvantages led to the development of the graphical software RELAP5-MV using extensive makeup language (XML) based on inner kernel model and solver of RELAP5 MOD 4.0 code. Utilized in actual numerical design of NPP, it is proven to raise modeling efficiency with RELAP5MV.

RELAP5-MV Visualized Modularization software is recognized as one of the best estimate transient simulation programs of LWR, in combination with new options for improved modeling methods, advanced programming, computational simulation techniques, and integrated graphics displays. RELAP5-MV software is based on RELAP5/MOD 4.0 thermal hydraulic best estimate. It has a visual simulation interface.

The platform can achieve two modeling objectives: one is the actual component-based modular modeling method, namely, the reactor, the steam generator, the pressurizer, the main pump, steam turbine and heat exchanger, and other real components. The other is the simplified block diagram representation of the system components in form of "control volume" as the basic unit of division and modeling and, for some special components, the direct application of the "special model" of the system, such as the main pump and valves. RELAP5-MV provides two types of modeling methods: component modeling method and modular modeling method. Component modeling method achieves system simulation task with experience of analyzing configuration and operating characteristics of modeling objects.

2.1. Software Interface Design. RELAP5-MV supplies a friendly human-computer interface through which users can build a system model more conveniently, rapidly, and visually. Figures $4-8$ show the main interface of RELAP5-MV, consisting of menu bar, toolbar, design sketch, navigation tree, component library, outline, and so forth. Functions of these parts are shown below. The software interface has the following components: hydraulic model, thermal component model, control system model, start or close logic signal, point heap dynamics model, and menu bar and toolbar as shown in Figure 4. The names and functions of these parts are as follows:

(i) Menu bar and toolbar: file operation (new, open, and save files generated by RELAP5-MV, icons adjustment in interface, RELAP5/MOD4.0 input file generating, calling RELAP5/MOD4.0 to start simulating calculation, etc.). 


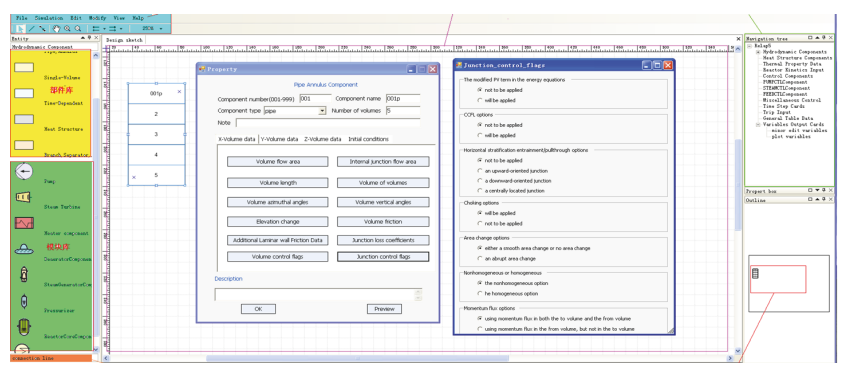

FIGURE 5: Main interface of RELAP5-MV.

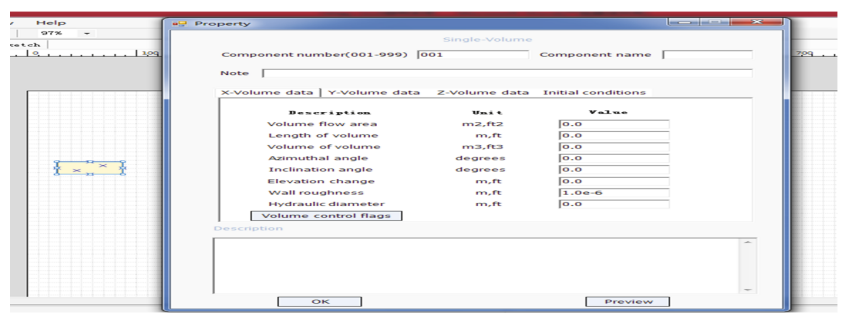

FIGURE 6: Single volume parameter input interface.

(ii) Design sketch: graphical module carrier.

(iii) Navigation tree: showing using status of input cards.

(iv) Library: collecting icons of components and modules, including component library and module library.

(v) Outline: thumbnail previews.

2.2. Modular Modeling. In order to meet the requirement of rapid modeling, modular modeling method is supported in RELAP5-MV, which is suggested to be used by freshman in RELAP5/MOD4.0 simulation field. Modular modeling method is a modeling method using device modules in the module library to build simulation system directly. For the already prepared NPP devices and modules with standard structures, functions and operating characteristics are collected in a module library embedded in RELAP5-MV. Filling in parameters step by step in each device and then connecting with junctions, simulation system could be established more rapidly. Thus, modular modeling method is able to act as one kind of technological means to realize rapid generation, validation, and assessment of nuclear reactor system design. During component modeling process, different kinds of node division strategies will be tested to find the optimized one not only to cover every part and achieve main functions and performances of the equipment, but to show the static and dynamic properties accurately by calculation results as well. In other words, component modeling method is fit for skilled researchers.

The main interface of the reactor core can be seen in Figure 5. Input data file will be generated automatically for RELAP5-MV simulating calculation in background due to the regulation format with necessary modeling data filled in the interface according to the prompt. These components are used in similar manner with other components.

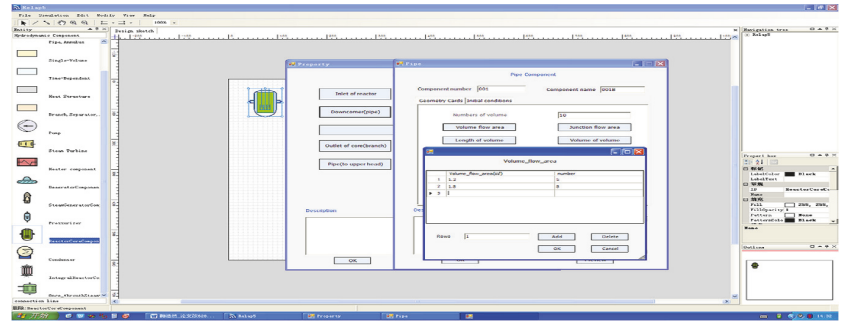

FIGURE 7: Filling parameters of device.

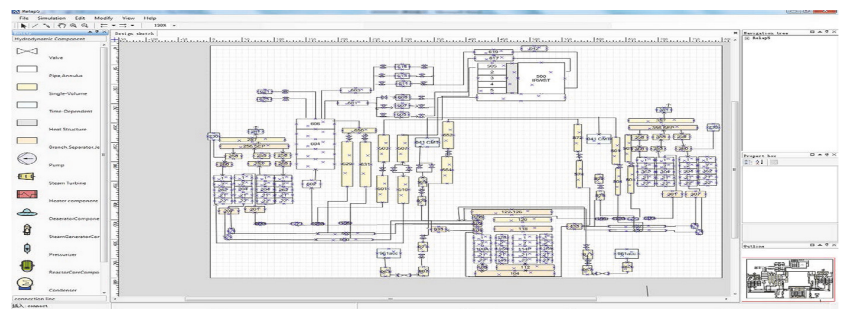

FIgURE 8: RELAP5-MV nodalization of AP1000.

Based on the description of each module above, after inputting and saving the parameters, the "generate input file (I file)" in the menu bar of simulation is clicked to start the simulation. One can also generate the current simulation system executable file, which can be called RELAP5-MOD4.0 calculation. RELAP5-MV interface is quite user friendly. Other reactor parameters and their respective values can be selected in the same way as demonstrated above.

2.3. Data Binding Functionality Advantage of RELAP5-MV. In contrast to the traditional way, users obtain calculation results given by RELAP5 as the RELAP5 built-in plot function, data output function, and data extraction with running strip file are complicated. Unfortunately, that requires multiple steps and much time while experiences in applying RELAP5 are needed, and this function is complex to use, whereas RELAP5-MV builds data binding function, which makes realizing data extraction and storage convenient. Key parameters of modules are bound to save in a certain database, such as pressure of inlet and outlet of core, temperature of core inlet and outlet, nuclear power, reactivity, pressure of SG inlet and outlet, water level, and pressure of pressurizer. Data above can be stored directly into database for system analysis and assessment.

\subsection{Modeling of AP1000 RELAP5-MV. A RELAP5-MV} model representing the transient analysis of AP1000 NPP has been developed, with the primary loop, partial secondary loop, and the passive safety system components of AP1000 considered. Figure 8 shows a view of the nodalization used in the simulation. A brief description of the nodalization scheme is given as follows. The nodalization was qualified as the results obtained from running the model at steady state were almost the same as that of the real plant values shown in Table 2. 
The reactor core is composed of a downcomer connecting to the lower head and the lower plenum. The fuel parts of the core are composed of two channels and a bypass region. Two direct vessel injection (DVI) nozzles are located in the upper downcomer and safety injection water from CMTs, accumulators, IRWST, and containment sump is supplied through the nozzles. Each steam generator model includes a separator, motor valves, downcomer, boiler, steam dome, and other essential components. There is a pressurizer connected to the hot leg of one of the steam generators equipped with safety relief valves. The action of safety and power operated relief valve (PORV) are controlled by trips as represented in the nodalization diagram. The two pumps included in each of the two loops are identical.

In this study, a small break LOCA is simulated by adding a trip valve and a time-dependent control volume (TMDPVOL) to the broken cold leg in the nonpressurizer side. The diagram shows the corresponding parts of the source for system simulation modeling. The parameters on the diagram can be controlled by the navigation tree on the right side of the window above. By pointing the cursor to the navigation tree, the user can enter the required parameters like thermal properties, editing, and graphics. Building the diagram with RELAP5 MOD4.0 follows exactly the same rules; the only difference is just incorporation of the user friendly graphic interface in RELAP5-MV. The main objective of graphical user interface (GUI) developed in the present work is to aid the RELAP user in preparation of input file [30]. RELAP5MV code can model the coupled characteristic of the RCS and the core for loss of coolant accident and operational transients such as anticipated transients without scram (ATWS), loss of offsite power, loss of feed-water, and loss of flow.

\section{Small Break LOCA Simulation and Accident Sequence}

3.1. Accident Process. In this study, the SBLOCA is simulated by considering a break in one of the cold legs in nonpressurized side of the primary loop. The break size considered is 10 inches which is maximum size of small break LOCA. The SBLOCA transient in AP1000 can be characterized into four (4) different phases which are the blowdown phase, ADS blowdown phase, natural circulation phase, and IRWST injection phase. At the start of SBLOCA, the leakage through the break results in drop of primary system pressure due to loss of energy and water inventory from the break [5]. During the accident, as the primary system pressure drops to $12.41 \mathrm{MPa}$, the control system automatically actuates the reactor trip. The actuation of reactor trip reduces the core power to decay heat level. The further primary system pressure drop generates safety actuation, a safeguard signal known as "S" signal at $11.72 \mathrm{MPa}$. The actuation of the core makeup tanks (CMT) and passive residual heat removal (PRHR) heat exchanger starts immediately after the " $S$ " signal. The main reactor coolant pumps trip follows the " $S$ " signal after a short time delay of $6 \mathrm{sec}[31,32]$. The natural circulation loop is established on actuation of core makeup tanks (CMTs). The CMTs inject cold borated water in the reactor core by gravity injection and receive hot water through the upper part of CMTs. The PRHR HX is immersed in the IRWST. The actuation of PRHR HX established another natural circulation loop. The hot water from hot leg enters into PRHR HX and transfers residual heat to the IRWST and the cold water is then injected into the primary system through cold leg. The further drop in the primary system pressure results in the actuation of two accumulators (ACCs) at $4.82 \mathrm{MPa}$. The ACCs are filled with cold borated water which is injected in the primary system through direct vessel injection (DVI) line. The high accumulator ejection flow rate temporarily impedes the CMT injection because accumulators and CMTs are connected on the same DVI line. The AP1000 reactor is equipped with $\mathrm{ADS}$. The main purpose of $\mathrm{ADS}$ system is to sequentially depressurize the primary system close to containment pressure and start the IRWST injection. IRWST injects cold water into the primary system by gravity for longterm cooling. The actuation of ADS depends on the water level in CMTs. The AP1000 automatic depressurization is divided into four (4) stages. The ADS stage 1 actuates when water level in either of the CMTs drops below 67.5\%. Stages two (2) and three (3) are designed to actuate at the specified time delay following ADS stage 1 [7]. The protection and safety monitoring system (PMS) set points and time delay assumed in the SBLOCA analysis for AP1000 are listed in Table 1 .

\section{Results and Discussion}

4.1. Steady-State Results. The steady-state analysis of AP1000 reactor is performed in RELAP5-MV by using AP1000 model as described in previous section. The comparison of the steady-state results obtained by the RELAP5-MV code, RELAP5 code, and the actual parameters of the AP1000 reactor is presented in Table 2 . It can be seen from the table that the calculated values are in close agreement with the actual AP1000 parameters.

4.2. SBLOCA Analysis and Comparison of Results Obtained from RELAP5-MV with NOTRUMP Code. In this work, 10inch small break LOCA is simulated by using the RELAP5$\mathrm{MV}$ in a cold leg of AP1000 in nonpressurizer loop. Table 1 presents the actuation set points of safety system during the small break LOCA.

The results obtained using RELAP5-MV and that by Westinghouse NOTRUMP code in addition to the results obtained using RELAP5 code were compared in Table 3 $[7,33]$. The calculated results show that the safety system actuation time sequence is closely related to the results of NOTRUMP code as shown by small differences in the values obtained.

The results obtain from SBLOCA analysis using RELAP5$\mathrm{MV}$ code in graphical form are compared with the Westinghouse results obtained through 10 -inch small break LOCA analysis using NOTRUMP code. As the LOCA starts, the primary system pressure drops due to break flow. The break flow causes mass and energy loss from primary loop and the primary system starts decreasing causing actuation of safety systems. With the actuation of all passive safety systems and ADS stages, the primary system finally attains the 
TABLE 1: AP1000 safety system actuation set point during SBLOCA [5].

\begin{tabular}{lcc}
\hline System/function & Actuation set points & Time delays (sec) \\
\hline Reactor trip & $12.41 \mathrm{MPa}$ & 2.0 \\
"S" signal generation & $11.72 \mathrm{MPa}$ & 2.0 \\
SG feed-water control valves start to close & After reactor trip signal & 3.2 \\
Main steam isolation valves start to close & After "S" signal & 4.8 \\
Reactor coolant pumps trip & After "S" signal & 6.0 \\
PRHRS isolation valve starts to open & After "S" signal & 0.0 \\
CMT actuation & After "S" signal & 0.0 \\
Accumulator actuation & 4.83 MPa & 0.0 \\
ADS-1 actuation & After CMT water volume reduces to $67.5 \%$ & 20.0 \\
ADS-2 actuation & 70 s after ADS-1 actuation & 30.0 \\
ADS-3 actuation & 120 s after ADS-2 actuation & 30.0 \\
ADS-4A actuation & $20.0 \%$ liquid volume fraction in CMT & 2.0 \\
ADS-4B actuation & $60 \mathrm{~s}$ after ADS-4A actuation & 2.0 \\
IRWST injection & Pressure $<89.6$ kPa + the containment pressure & 2.0 \\
\hline
\end{tabular}

TABLE 2: Steady-state calculated results of AP1000 obtained by the RELAP5-MV.

\begin{tabular}{lccc}
\hline Parameters & RELAP5-MV results & Actual value [7] & RELAP5 value [5] \\
\hline Core thermal power (MW) & 3415.00 & 3400.00 & 3483.30 \\
RCS pressure $(\mathrm{MPa})$ & 15.60 & 15.52 & 15.52 \\
Vessel inlet temperature (K) & 553.90 & 553.82 & 553.85 \\
Vessel outlet temperature (K) & 595.00 & 594.26 & 594.29 \\
Vessel average temperature (K) & 585.00 & 574.04 & 574.07 \\
SG secondary pressure (MPa) & 5.61 & 5.61 & 5.61 \\
SG feed-water temperature (K) & 499.83 & 499.82 & 499.82 \\
\hline
\end{tabular}

containment pressure and results in actuation of IRWST. The pressure drop during small break LOCA calculated from RELAP5-MV and NOTRUP is given in Figures 9 and 10, respectively. In such a way the system pressure drops to near atmospheric pressure. Finally, the system pressure becomes stable until the end of the transient. The general trend of the system pressure depressurization is in a good agreement between the RELAP5-MV and NOTRUMP code used by Westinghouse.

During primary system pressure drop, the reactor scram initiated as the primary system pressure drops to $12.41 \mathrm{MPa}$ and reactor power reaches decay heat level. Figure 11 shows the nuclear power during small break LOCA. The " $\mathrm{S}$ " signal is generated when primary system pressure reduction reaches 11.72 MPa. The generation of "S" signal actuates the injection through CMT and PRHR HX.

The reactor coolant pumps stop with a short time delay after "S" signal generation which results in reduction coolant flow through the break.

After a short delay, the "S" signal trips the reactor coolant pumps. This reduces coolant loss through the break.

The break flow rate during small break LOCA as obtained through RELAP5-MV and NOTRUMP is shown in Figures 12 and 13, respectively. The break flow is usually of two phases: the subcooled blowdown phase and the two-phase blowdown phase. The former is at the onset of the accident and it is characterized by decreasing pressure to the saturation pressure with a high break flow rate and remains only for a short

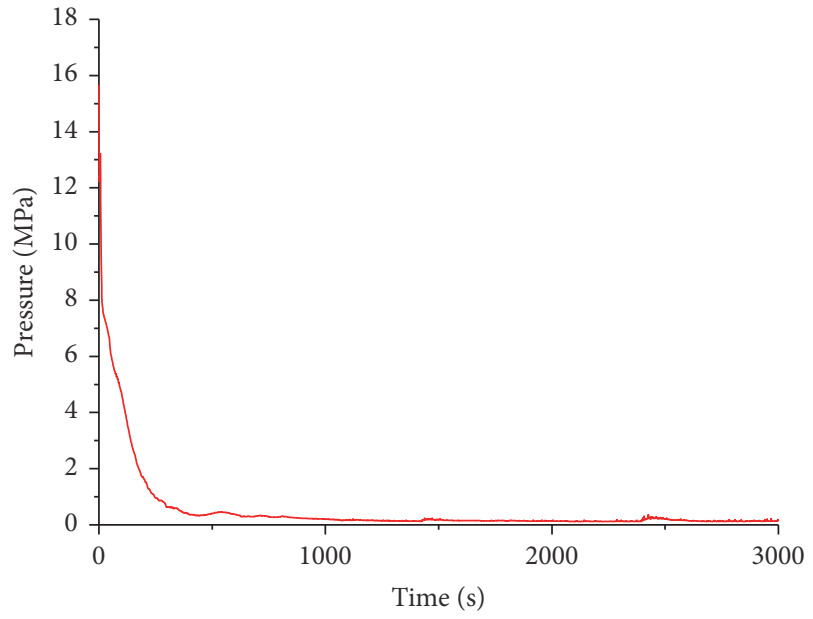

FIGURE 9: RCS pressure transient (RELAP5-MV).

time while the latter decreases the reactor coolant pressure and lasts for the remaining time of the accident [34, 35]. The results are nearly similar. However, the slight differences observed in the graphs are probably due to differences in models on which the codes are based, nodalization schemes adopted, and underlining assumptions made by the authors. It is obvious from the results that the actuation of CMTs and accumulators causes rapid increase in break flow. 
TABLE 3: Sequence of events during 10-inch SBLOCA in AP1000 by RELAP5-MV and NOTRUMP.

\begin{tabular}{lccc}
\hline Event & REALP5-MV & NOTRUMP [7] & RELAP5 [5] \\
\hline Break opens & 00.0 & 00.0 & 5.2 \\
Reactor trip signal & 5.5 & 6.4 & 4.7 \\
"S" signal & 8.0 & 8.4 & 6.5 \\
Main feed isolation valves begin to close & 8.2 & 11.2 & 7.9 \\
Steam turbine stop valves close & 9.8 & 12.4 & 11.4 \\
Reactor coolant pumps start to coast down & 12 & 85.0 & 12.5 \\
Accumulator injection starts & 94 & 418.2 & 106.6 \\
Accumulator-1 empties & 440 & 425.5 & 385.4 \\
Accumulator-2 empties & 442 & 750.0 & 390.0 \\
ADS stage 1 & 732 & 820.0 & 728.8 \\
ADS stage 2 & 802 & 940.0 & 798.8 \\
ADS stage 3 & 922 & 1491.0 & 918.8 \\
ADS stage 4 & 1181 & 41284 \\
\hline
\end{tabular}

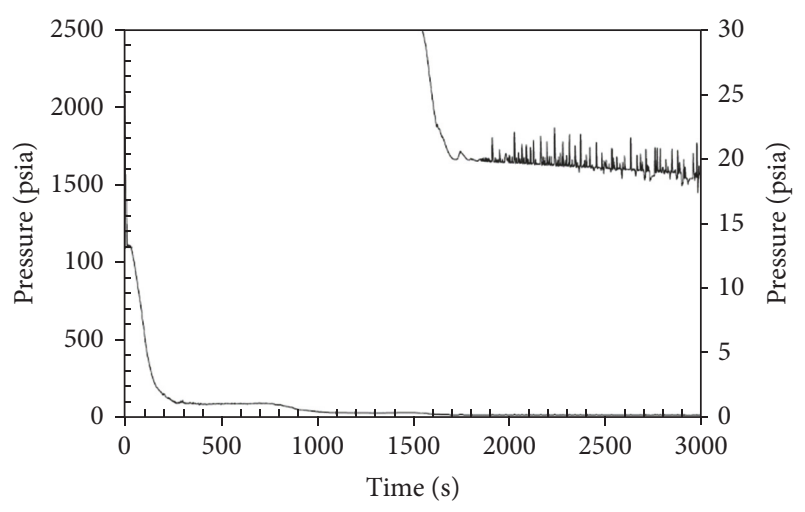

Figure 10: 10-inch Cold Leg Break, RCS pressure (NOTRUMP code) [7].

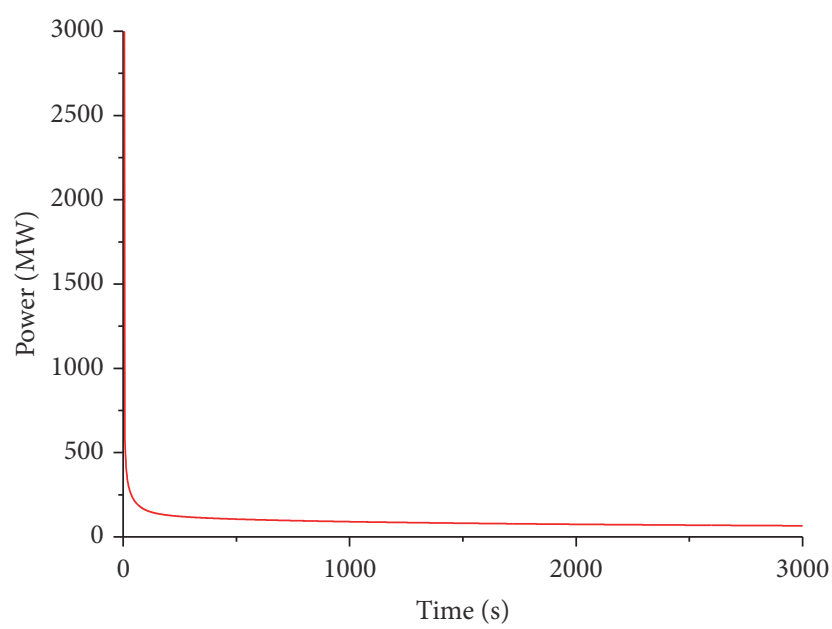

FIGURE 11: Nuclear power.

The actuation of CMT results in injection of relatively cold borated water into the primary system. The upper part of CMT is connected with one of the cold legs and the relatively hot water is collected into the CMT from cold leg and a loop

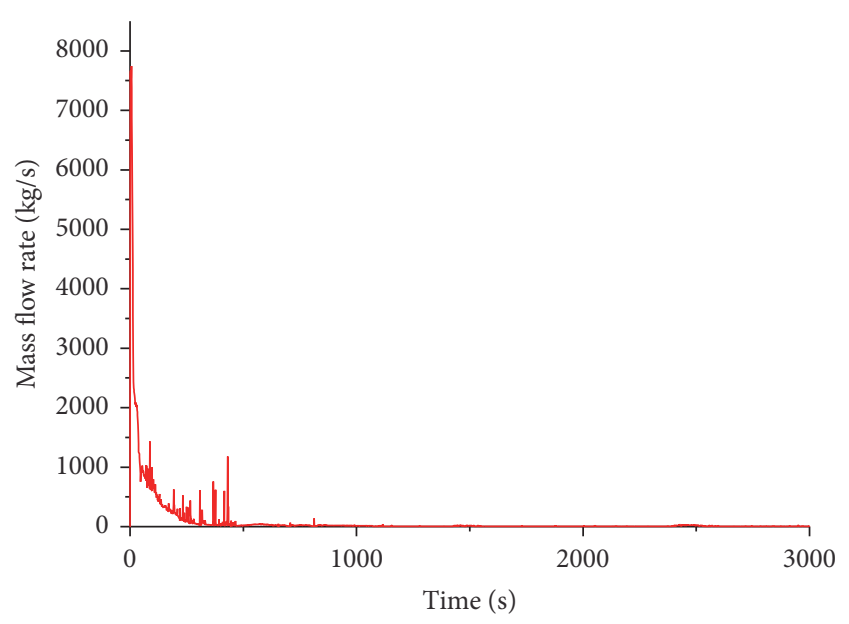

FIGURE 12: Liquid break discharge flow rate.

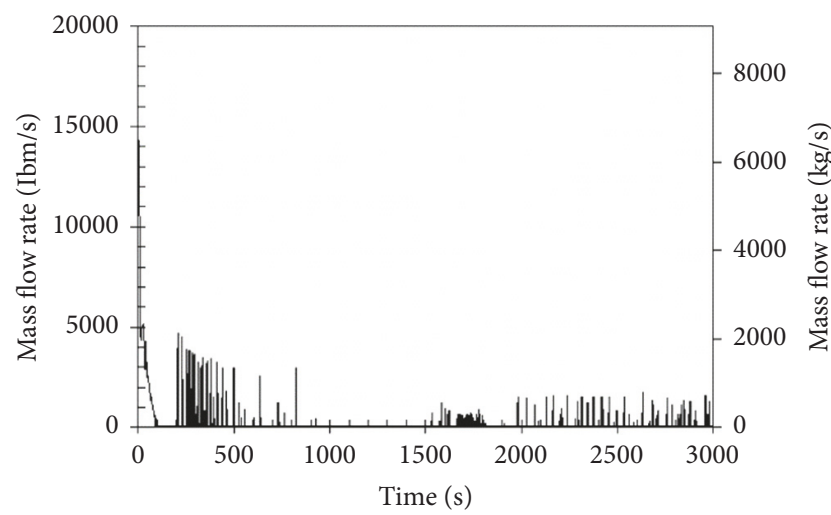

FIGURE 13: 10-inch liquid break discharge (NOTRUMP code) [7].

is established due to natural circulation flow. This natural circulation flow through CMT is called recirculation mode [10]. Similarly, the IRWST actuation also causes a natural circulation flow. The heat of hot coolant is transferred to the IRWST and the relatively cold and heavier water is injected 


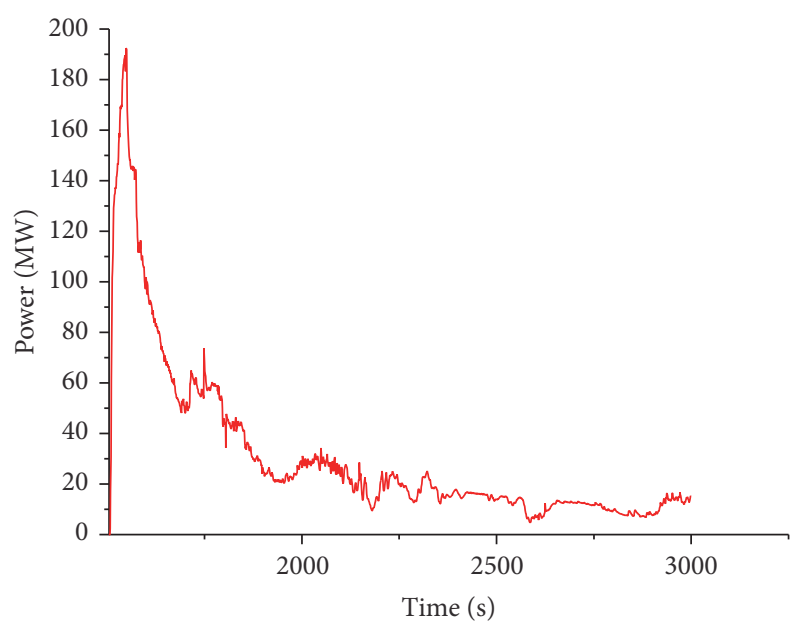

FIGURE 14: PRHRS heat removal rate.

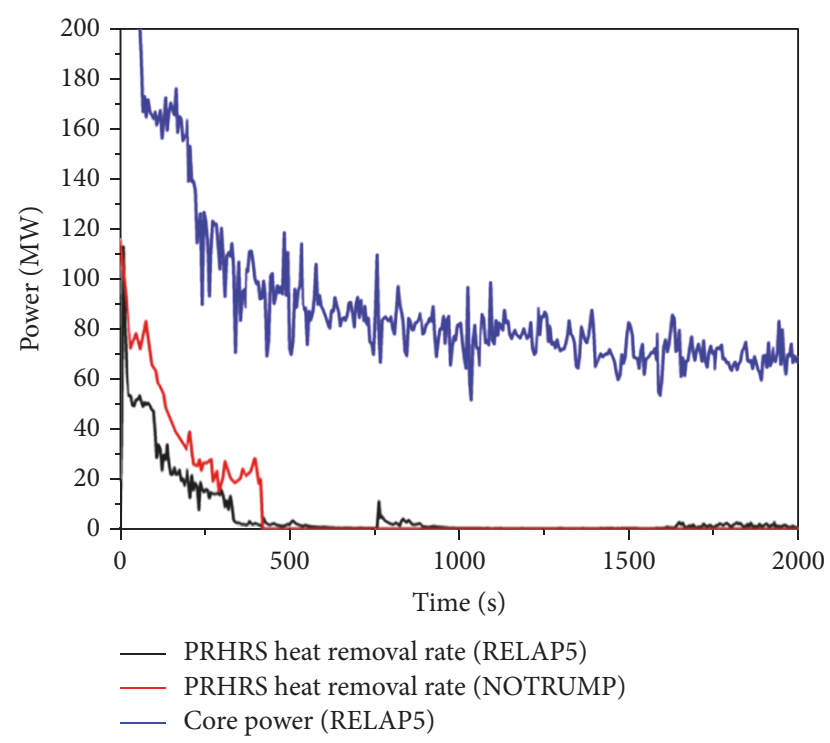

FIGURE 15: PRHRS heat removal rate from NOTRUMP code [5].

into the primary system. The CMT draining mode will start when the hot coolant collection stops at the top of the CMT [36]. Figures 14 and 15 show the PRHRS heat removal rate. The heat removal rate through PRHR HX reduces during LOCA due to reduction in flow through the PRHR HX. The results of RELAP5-MV and NOTRUMP are nearly similar as shown in Figures 14 and 15. However, the difference in results may be due to the different solution methodologies adopted in both software systems, that is, RELAP5-MV and NOTRUMP. The difference may also be caused by difference in nodalization schemes. As described earlier, the CMT recirculation mode is converted to CMT draining mode when the water level in the line connecting the cold leg and upper part of CMT starts draining. The CMT draining mode causes the reduction in CMT level. The actuation set point of ADS stage 1 is related to the CMT level and reduction in CMT level actuated the automatic depressurization system. Comparison of CMT flow rate obtained from REPLAP5-MV

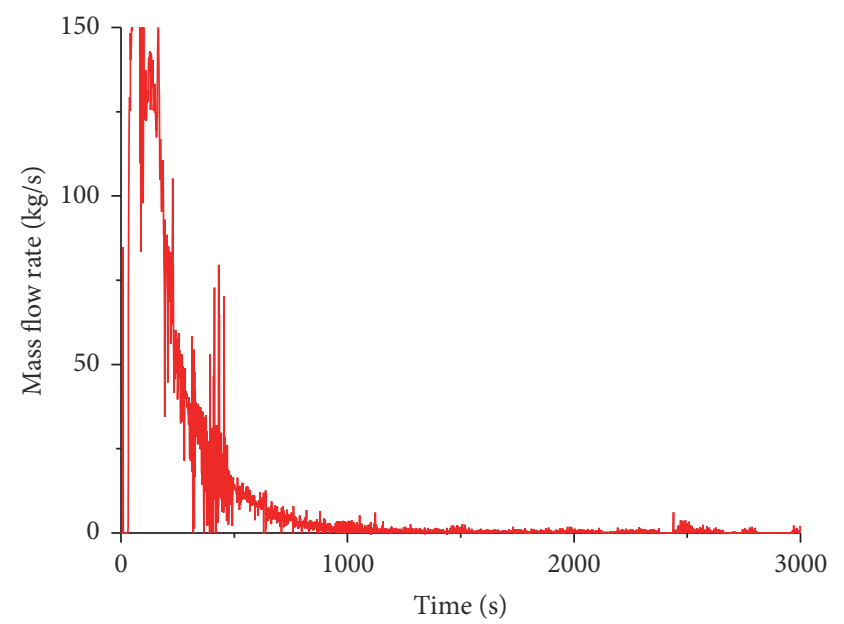

FIGURE 16: CMT-1 injection rate.

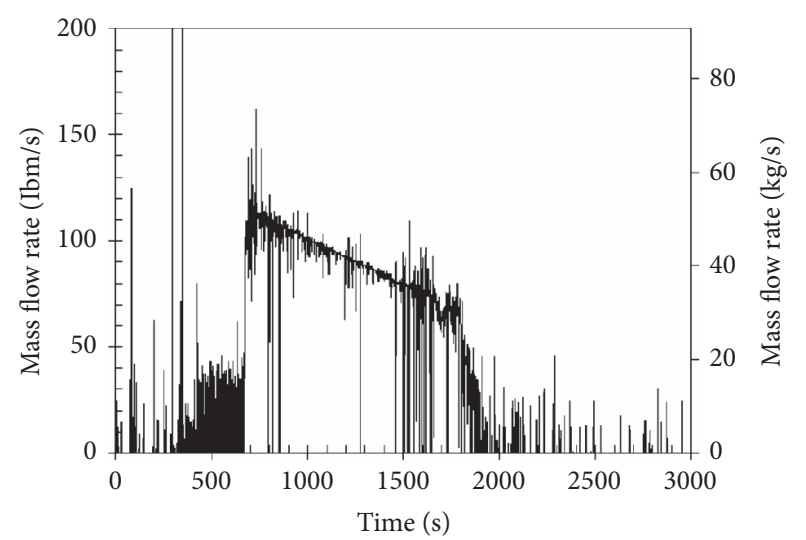

FIgure 17: 10-inch Cold Leg Break: CMT-1 (NOTRUMP code) [7].

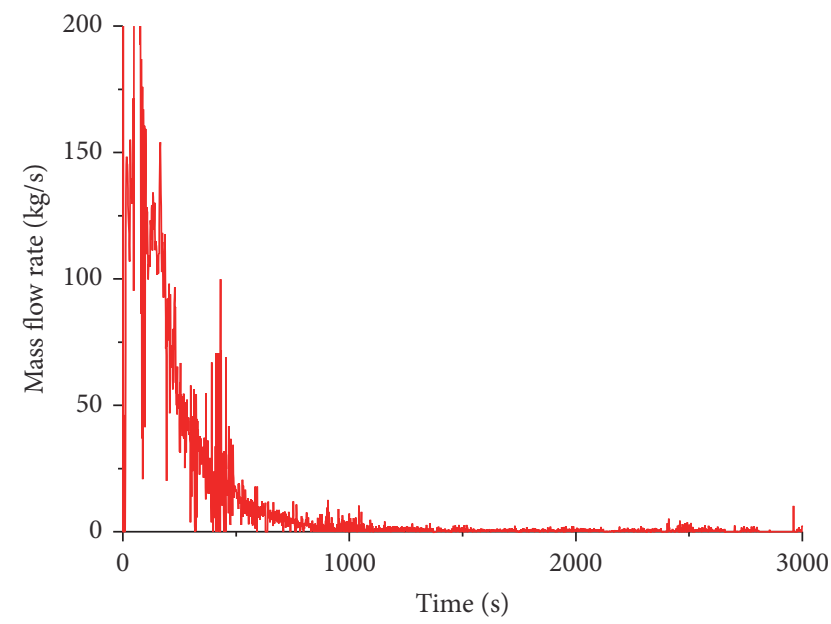

FIGURE 18: CMT-2 injection rate.

and NOTRUMP code is shown in Figures 16, 17, 18, and 19. The qualitative difference observed for the CMT-2 injection flow is as a result of the different methodologies the two codes are based upon. Comparison is made between NOTRUMP and RELAP5-MV with the same experiment, that is, 10-inch LOCA in cold leg. The results are compared. The trend is 


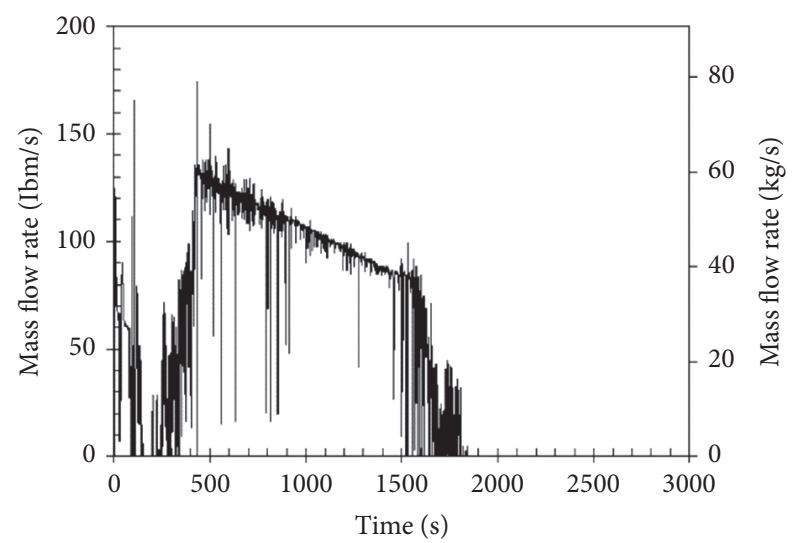

FIgURE 19: 10-inch Cold Leg Break: CMT-2 (NOTRUMP code) [7].

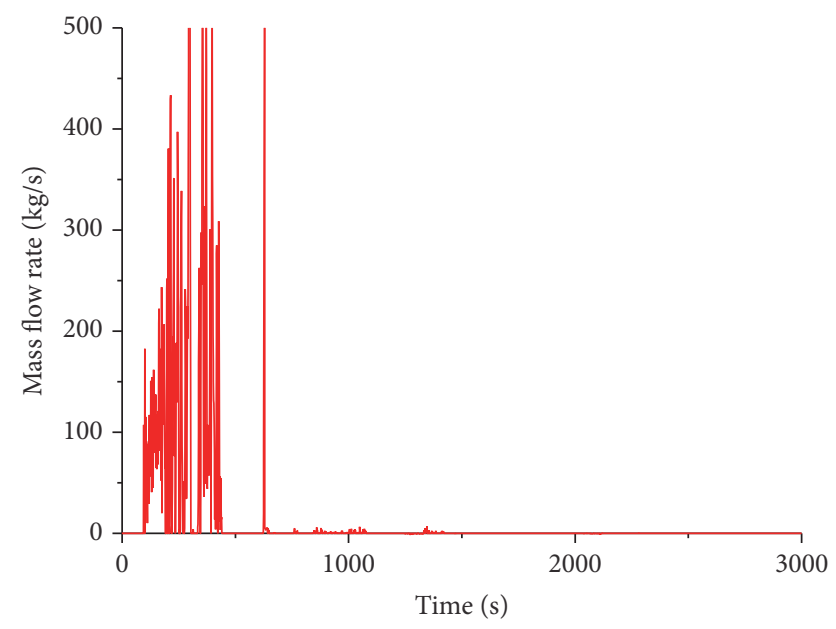

Figure 20: Accumulator-1 injection rate.

similar; however, there may be difference in the values due to different codes, different nodalization scheme, and necessary assumptions made by the authors.

The accumulator injection starts when the primary system pressure reduces to $4.83 \mathrm{MPa}$. The accumulators also inject relatively cold borated water into the reactor core through direct vessel injection line. ACCs and CMT are connected to the DVI line, and the relatively high accumulator flow temporarily reduces the CMT flow due to back pressure $[10,37,38]$. The calculated results through RELAP5-MV show that the accumulator injection starts at $t=94 \mathrm{sec}$ and the accumulators become empty at around $t=440 \mathrm{sec}$ as shown in Figures 20, 21, 22, and 23 [38]. The sudden increase at first and then decreasing trend of flow through the accumulators as displayed in the above-mentioned figures is because of the pressure difference between the accumulator compressed gas and the primary system pressure [5]. ACC and CMT are connected on the same DVI line. Therefore, the flow through CMT and accumulator affects each other's flow. The oscillation in accumulator flow may be due to back pressure exerted by CMT flow and vice versa.

The actuation of ADS stages start when the CMT water level reaches $67.5 \%$. The ADS actuation causes the further

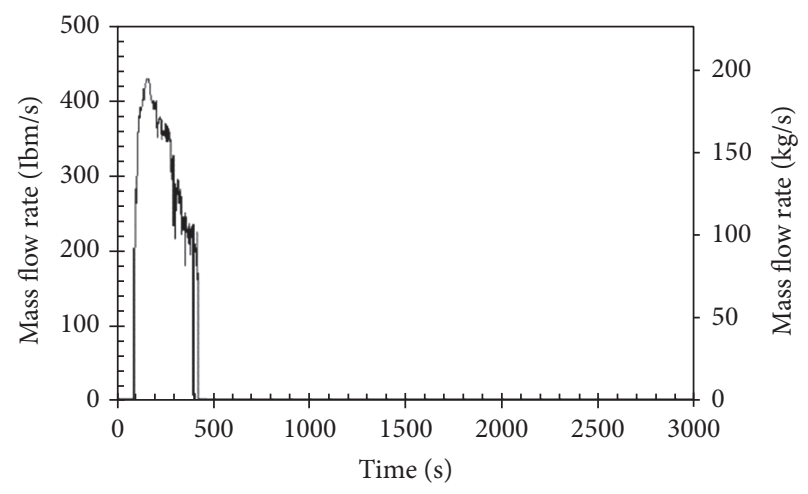

FIGURE 21: 10-inch Cold Leg Break: Accumulator-1 (NOTRUMP code) [7].

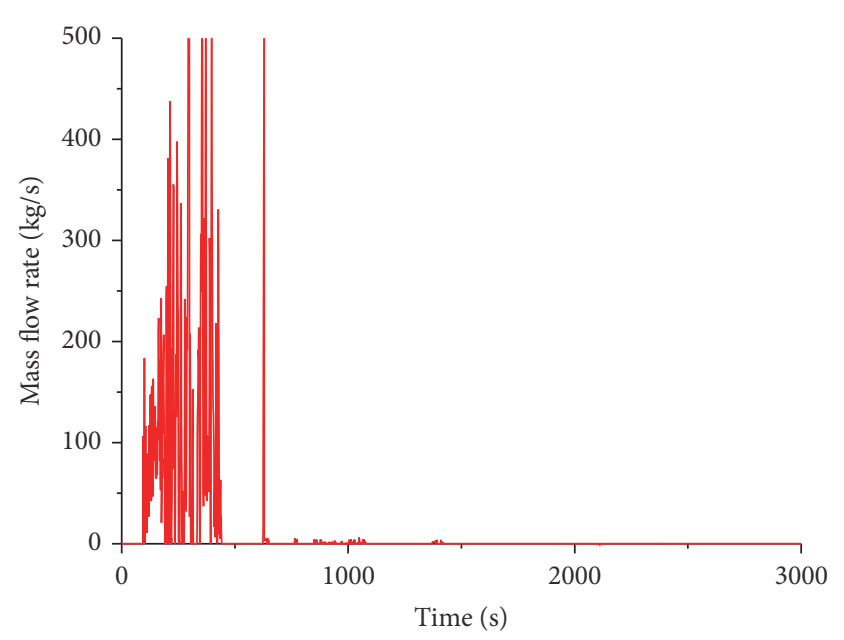

FIGURE 22: Accumulator-2 injection rate.

rapid reduction in primary system pressure. The flow through ADS stages is given in Figures 24, 25, and 26. The discharge flow is higher in ADS stages 2 and 3 as compared with the ADS stage 1 due to relatively large diameter of ADS stages 2 and 3 [7]. The calculated results show that the ADS stage 1 actuates at $t=732 \mathrm{sec}$ and the ADS stages 2 and 3 actuate at $t=802 \mathrm{sec}$ and $t=922 \mathrm{sec}$, respectively.

The further reduction in CMT level causes the actuation of ADS stage 4 at 20\% CMT level. The simulated results show that the ADS stage 4 is actuated at around $t=$ $1181 \mathrm{sec}$. The flow rate through ADS stages $4 \mathrm{~A}$ and $4 \mathrm{~B}$ obtained through REPA5-MV is given in Figures 27 and 28, respectively. The flow rate through ADS stage 4 as calculated by Westinghouse and mentioned in AP1000 design control documents is shown in Figure 29. The comparison of ADS stage 4 results indicates that both codes, that is, RELAP5-MV and NOTRUMP, provide similar results.

The actuation of ADS stages causes effective and more rapid primary system depressurization and reduces the primary system pressure to the containment pressure and the gravity driven IRWST injection starts. The large water storage in IRWST results in core cooling for longer period of time. 


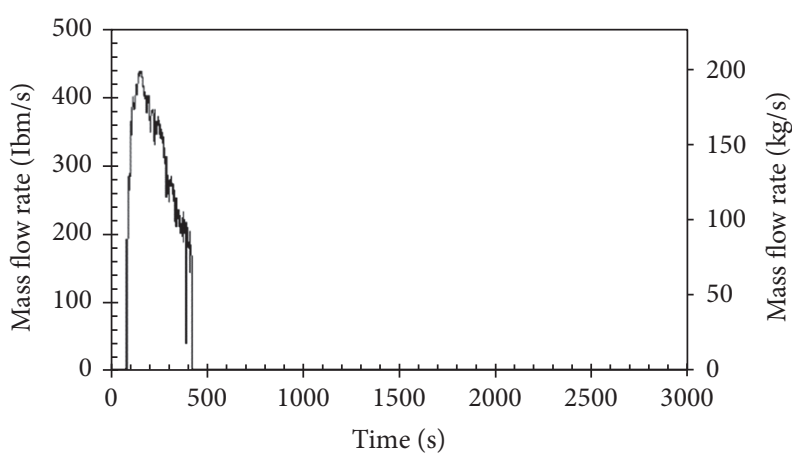

FIGURE 23: 10-inch Accumulator-2 injection rate (NOTRUMP code) [7].

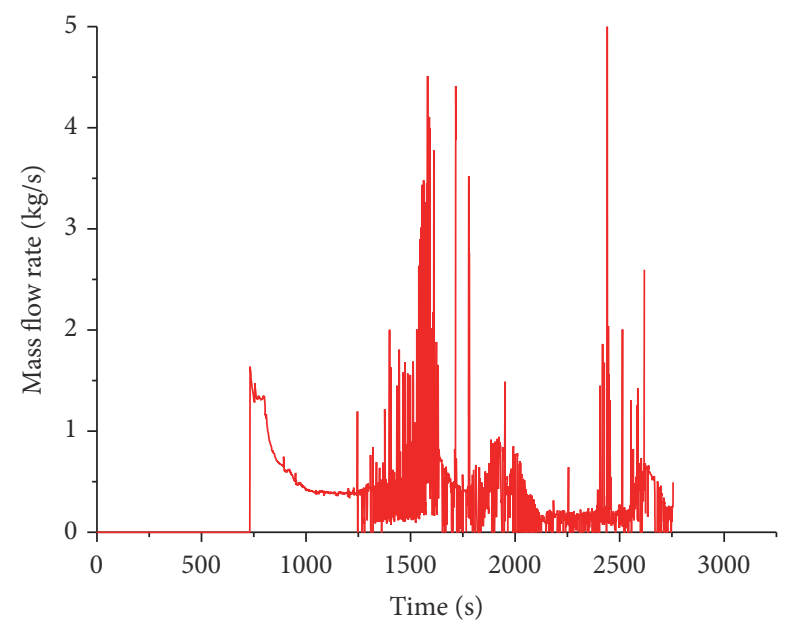

FIGURE 24: ADS-1 discharge flow rate.

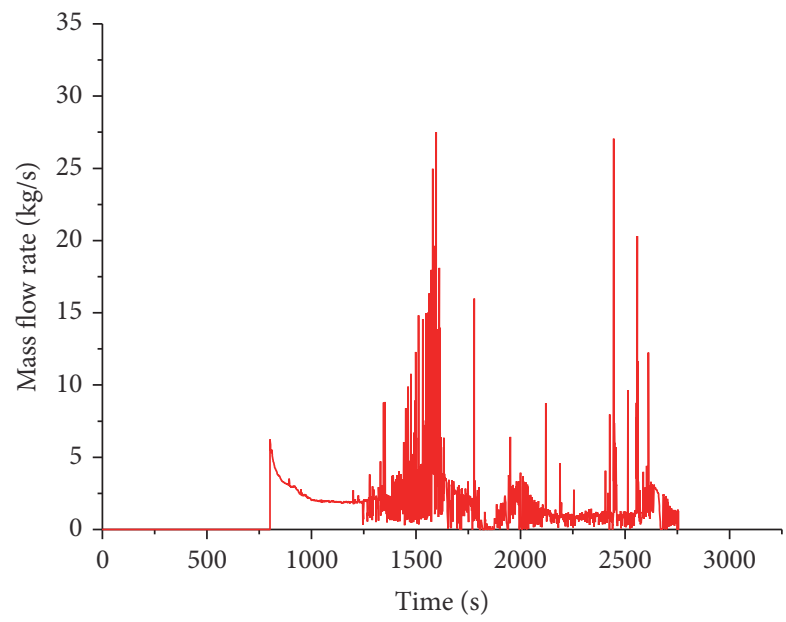

Figure 25: ADS-2 discharge flow rate.

The fuel rod temperatures are important to monitor during LOCA. The cladding inner wall temperature during small break LOCA sequence is shown in Figure 30 as calculated through RELAP5-MV. After reactor shutdown, the cladding temperature reduces continuously due to no

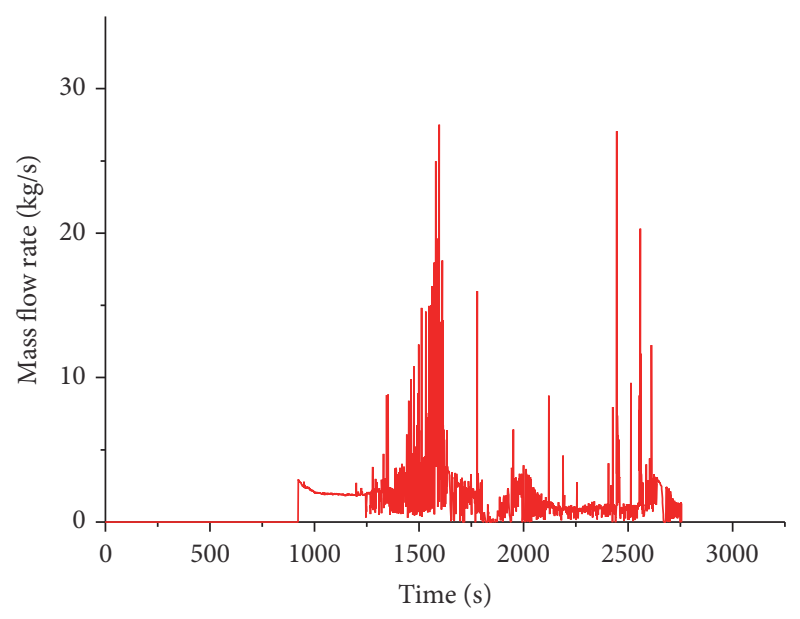

Figure 26: ADS-3 discharge flow rate.

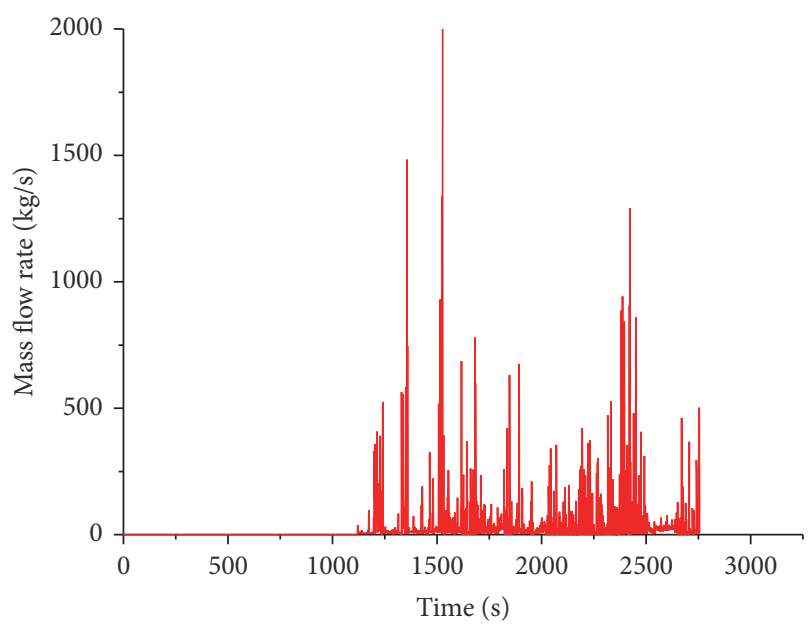

FIGURE 27: ADS-4A discharge flow rate.

stoppage of fission chain reaction and effective heat removal by actuation of passive safety systems.

The analysis and comparison of simulated results obtained from RELAP5-MV show that the code is capable of simulating the plant behavior appropriately during small break LOCA similar to NOTRUMP.

\section{Conclusions}

RELAP-MV Visualized Modularization software is recognized to be one of the best estimate transient simulation programs of light water reactor as it has new options for improved modeling methods, advanced programming, computational simulation techniques, and integrated graphics displays.

In this study, RELAP5-MV is applied for simulation and analysis of the thermohydraulic behavior and operation of passive safety systems.

The SBLOCA is simulated in one of the cold legs in nonpressurized side of the primary loop, with 10 -inch break 


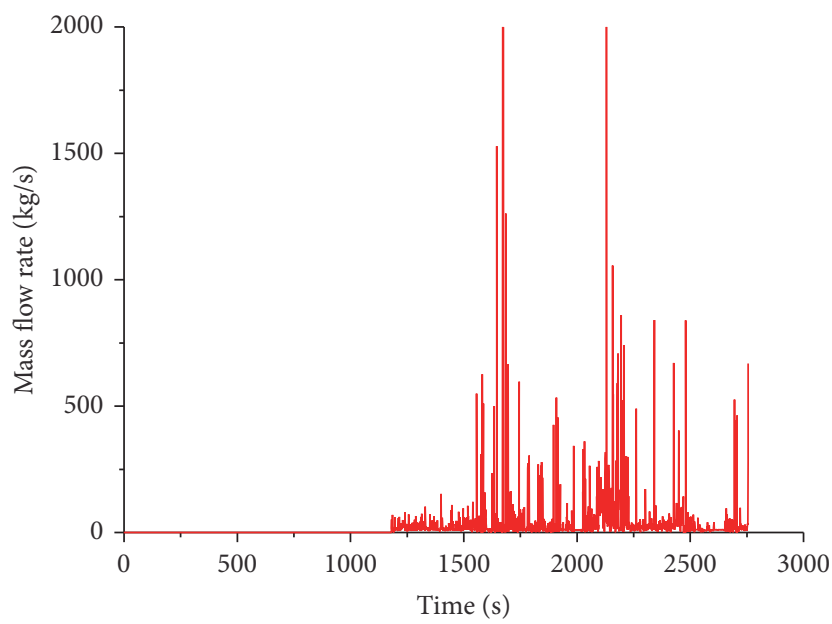

FIGURE 28: ADS-4B discharge flow rate.

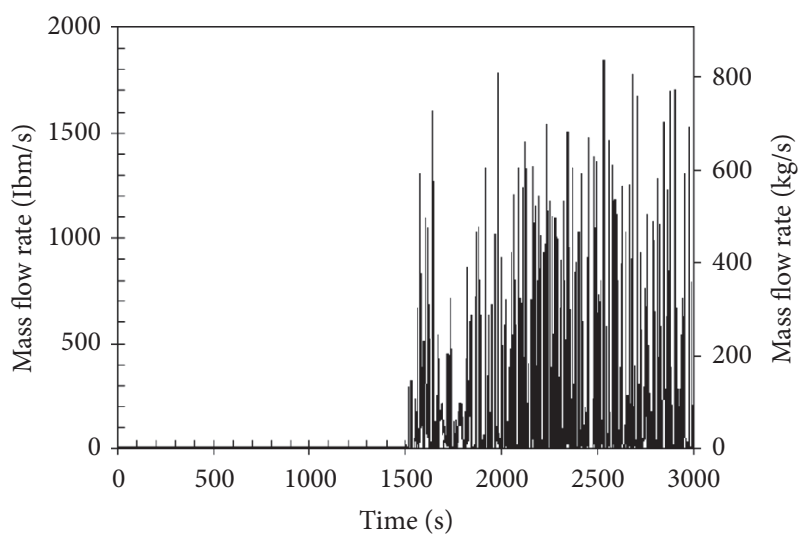

FIgURE 29: 10-inch Cold Leg Break: ADS-4 (NOTRUMP code) [7].

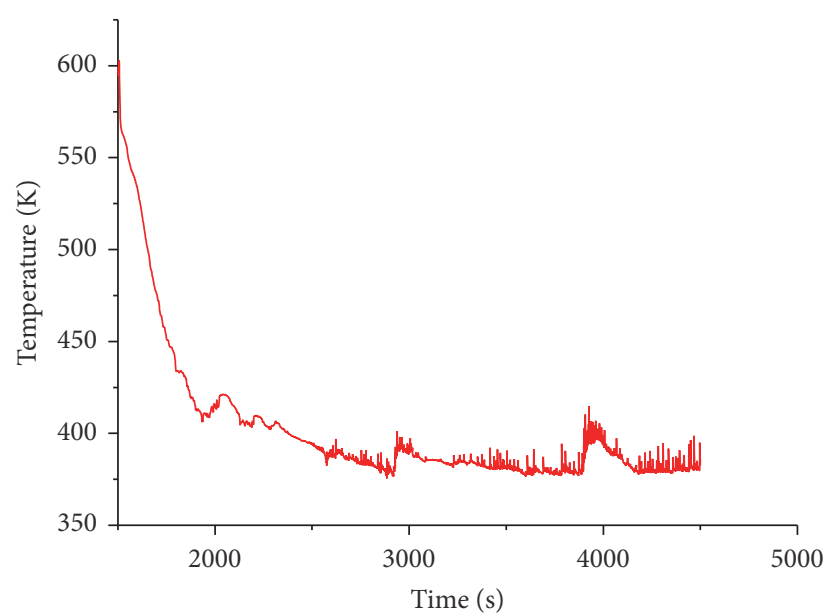

Figure 30: Temperature on the cladding inner wall.

size. The results and accident sequence are compared with that of NOTRUMP code as obtained by Westinghouse.

The RELAP5-MV results are in good agreement with that of NOTRUMP code. Based on the results obtained, RELAP5MV predicts the plant behavior correctly. RELAP5-MV is able to simulate a SBLOCA scenario in a similar manner to NOTRUMP code.

RELAP5-MV has a friendly human-computer interface through which users can build a system model more conveniently, rapidly, and visually. It also makes simulation of nuclear power systems easier and convenient for users most especially beginners. Finally, with RELAP5-MV the generation and modification of input file are made very simple.

\section{Conflicts of Interest}

The authors declare that they have no conflicts of interest.

\section{Acknowledgments}

Eltayeb Yousif would like to express his gratitude to his supervisor Professor Zhijian Zhang and Professor Zhaofei Tian, and also he would like to thank his colleagues at Harbin Engineering University.

\section{References}

[1] M. M. Corletti, "AP1000 Plant Description and Analysis Report," Tech. Rep., Westinghouse Electric Company, LLC, 2000.

[2] http://www.westinghousenuclear.com/New-Plants/AP1000PWR/Safety.

[3] H. Xie and S. He, "The SCDAP/RELAP5 3.2 model of AP1000 on SBLOCA," Progress in Nuclear Energy, vol. 61, pp. 102-107, 2012.

[4] D. Lioce, M. Asztalos, A. Alemberti, L. Barucca, M. Frogheri, and G. Saiu, "AP1000 passive core cooling system preoperational tests procedure definition and simulation by means of Relap5 Mod. 3.3 computer code," Nuclear Engineering and Design, vol. 250, pp. 538-547, 2012.

[5] J. Yang, W. W. Wang, S. Z. Qiu, W. X. Tian, G. H. Su, and Y. $\mathrm{W}$. Wu, "Simulation and analysis on 10-in. cold leg small break LOCA for AP1000," Annals of Nuclear Energy, vol. 46, pp. 81-89, 2012.

[6] N. R. José, "Behavior of emergency heat exchangers and isolation condensers," in 3rd Research Coordination Meeting of the IAEA CRP on Natural Circulation Phenomena, Modeling and Reliability of Passive Systems that Utilize Natural Circulation, Cadarache, France, 2006.

[7] "Westinghouse AP1000 Design Control Document," Tech. Rep., Westinghouse Electric Company, 2004.

[8] L. L. Zheng Limin, "Analysis of reactor coolant system leak for AP1000 nuclear power plant," Nuclear Techniques, vol. 39, p. 9, 2016.

[9] N. R. José, "AP600 and AP1000 Passive Safety System Design and Testing in APEX," IAEA Course on Natural Circulation in Water - Cooled Nuclear Power Plants, International Centre for Theoretical Physics (ICTP), Italy, 2004.

[10] R. F. Wright, "Simulated AP1000 response to design basis small-break LOCA events in APEX-1000 test facility," Nuclear Engineering and Technology, vol. 39, pp. 287-298, 2007.

[11] W. Grush, "Pygmalion Software," Tech. Rep., Idaho National Engineering Laboratory, 1982. 
[12] R. Fink, R. Callow, T. Larson, and V. Ransom, "ATHENAAide - An Expert System for ATHENA Code Input Model Preparation," in The Artificial Int. and Innovative Computer Applications in Nuclear Industry Meeting, ANS, 1987.

[13] F. Bastenaire, Y. Crommel ynick, K. Dejongh, M. De Vlaminck, and L. Vanhoenacker, "Tropic: users manual," Version 4.0, Tractebel, 1992.

[14] B. Gitnick, "SNAP development status," in Proceeding of the 13th CAMP meeting, October, 1998.

[15] D. Snider, K. Wagner, W. Grush, and K. Jones, "Nuclear plant analyzer: computer visual system reference manual," NUREG/ CR-6291, INEL-94/0123, 1995.

[16] IAEA and SEI MELSIM/RELSIM, "MELSIM/RELSIM v. 2.1 User's Guide, UNIPUB, 4611-F Assembly Drive," 2.1 Users Guide, UNIPUB, 4611-F Assembly Drive, November 1999.

[17] K. Jones and J. Fisher, "XMGR5 users manual," INEL/EXT-9700346 INEL/EXT-97-00346, National Engineering and Environmental Laboratory, 1997.

[18] G. Mesina and A. Austin, "New RELAP5 graphical user interface," in Proceedings of the International RELAP5 Users Seminar, Dallas, Tx, USA, 1996.

[19] G. Mesina, “The RELAP5 3D Station, a Graphical User Interface," in Proceedings of the International RELAP5-3D Users Seminar, College Station, TX, USA, 1998.

[20] G. Mesina and J. Galbraith, "RELAP5-3D Graphical User Interface," in RGUI 1.1, Proceedings of the International RELAP5-3D Users Seminar, p. 13, Park City, UT, USA, 1999.

[21] D. M. Snider, K. L. Wagner, W. H. Grush, and K. R. Jones, "Nuclear Plant Analyzer, U.S. NRC report, NUREG/CR-6291, , Idaho National Engineering Laboratory," INEL-94/0123, 1997.

[22] APT, Symbolic nuclear analysis package (SNAP), user's manual, applied programming technology (APT), APT, Inc, Applied Programming Technology, 2007.

[23] K. Murata, D. Williams, R. Griffith et al., "Code manual for CONTAIN 2.0: a computer code for nuclear reactor containment analysis," Tech. Rep. NUREG/CR-6533, 1997.

[24] U. S. NRC, "RELAP5/MOD3.3 code manual," Vols, vol. 1-8, 2010, to 8, U.S. NRC report, NUREG/CR-5535/Rev P4.

[25] U. S., "Division of Risk Assessment and Special Projects," in TRACE V5.0p2 User's Manual, Division of Risk Assessment and Special Projects, Office of Nuclear Regulatory Research, DC, Washington, 2010.

[26] C. M. Allison, U. Luettringhaus, B. S. Allison, and J. K. Hohorst, "Application of RELSIM-RELAP/SCDAPSIM for university training and simulator development," in Proceedings of the 18th International Conference on Nuclear Engineering, ICONE18, chn, May 2010.

[27] K. D. Kim and Rizwan-uddin, "A web-based nuclear simulator using RELAP5 and LabVIEW," Nuclear Engineering and Design, vol. 237, no. 11, pp. 1185-1194, 2007.

[28] M. H. Talukder, "Modelling of the Pactelsbl-50 Transient Using RELAP5 Computer Code Department of Nuclear Engineering," Modelling of the Pactelsbl-50 Transient Using RELAP5 Computer Code Department of Nuclear Engineering, vol. 262, pp. 16534662, 2012.

[29] "RELAP5/MOD3 code manual: User's guide and input requirements. Volume 2," Tech. Rep. NUREG/CR-5535-Vol.2, 1995.

[30] R. R. Schultz, RELAP5 Code Manual Volume V: Users Guidelines, Idaho National Engineering and Environmental Laboratory Bechtel BWXT, Idaho, 2002.
[31] M. T. Friend, R. F. Wright, R. Hundal, L. E. Hochreiter, and M. Ogrins, "Simulated AP600 response to small-break lossof-coolant-accident and non-loss-of-coolant-accident events: analysis of SPES-2 integral test results," Nuclear Technology, vol. 122, no. 1, pp. 19-42, 1998.

[32] A. K. Muftuoglu, Improved methodology for integral analysis of advancedreactors employing passive safety, ph.d. thesis. the pennsylvania stateuniversity [ph.d. thesis], USA, 2004.

[33] WEC, "Control Document, Westinghouse ElectricCompany, Revision 17," LLC, 2008.

[34] R. B. Zhou, F. C. Li, G. H. Xu, R. Q. Yao, and G. F. Wei, "Experimental investigation on $1 \%$ small break loss-of-coolant accident of pressurized water reactor cold leg," At. Energy. Sci. Technol, vol. 32, 1998.

[35] H. C. No, "Decay heat removal and operators intervention during a very small LOCA," Journal of Korean Nuclear Society, vol. 16, no. 1, pp. 11-17, 1983.

[36] W. E. Burchill, "Physical phenomena of a small-break loss-ofcoolant accident in a PWR," Nuclear Safety, vol. 23, no. 5, pp. 525-536, 1982.

[37] T. Yonomoto, M. Kondo, Y. Kukita, L. S. Ghan, and R. R. Schultz, "Core makeup tank behavior observed during the ROSA-AP600 experiments," Nuclear Technology, vol. 119, no. 2, pp. 112-122, 1997.

[38] A. Elshahat, T. Abram, J. Hohorst, and C. Allison, "Simulation of the Westinghouse AP1000 response to SBLOCA using RELAP/SCDAPSIM," International Journal of Nuclear Energy, vol. 2014, 9 pages, 2014. 


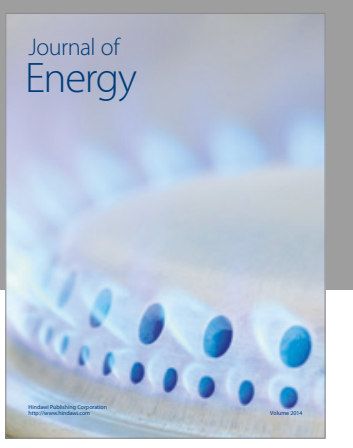

Journal of

Industrial Engineering
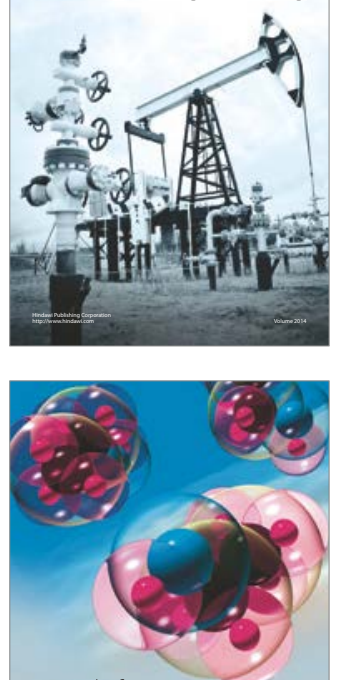

Fuels
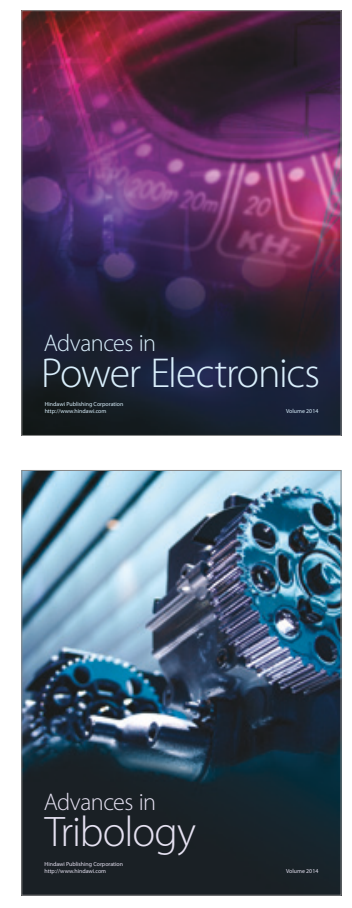
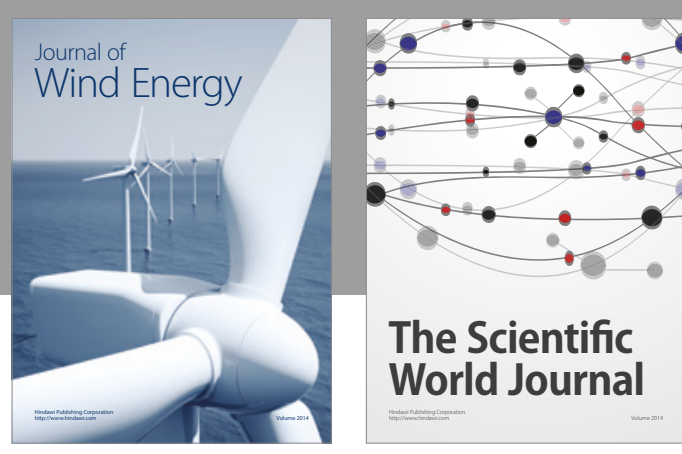

The Scientific World Journal
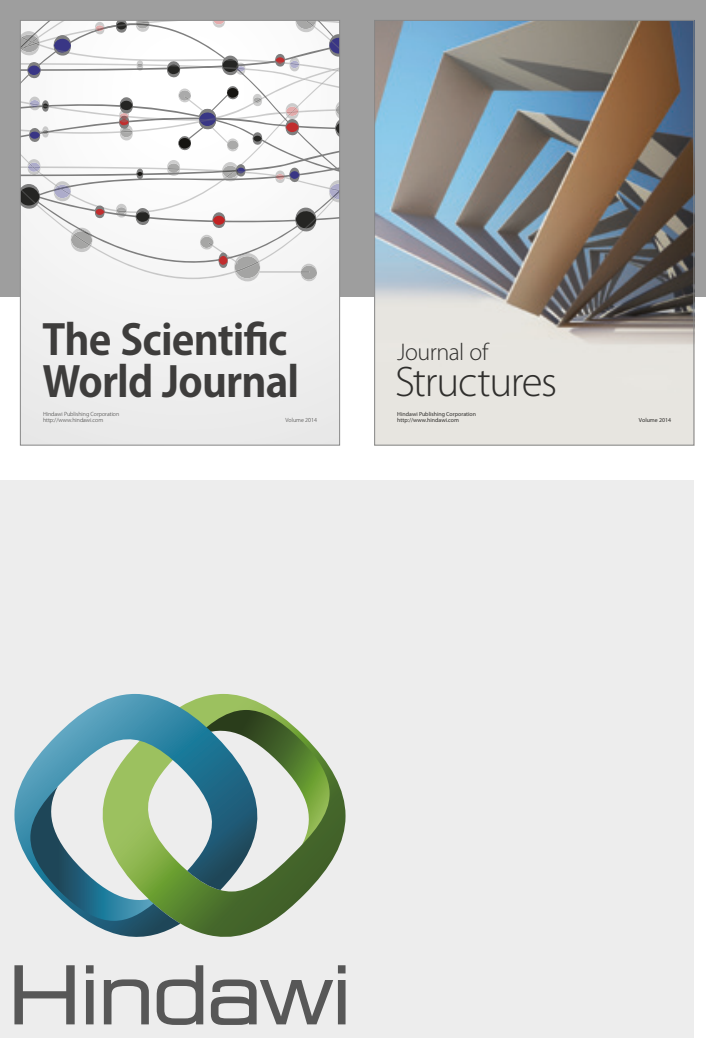

Submit your manuscripts at

https://www.hindawi.com
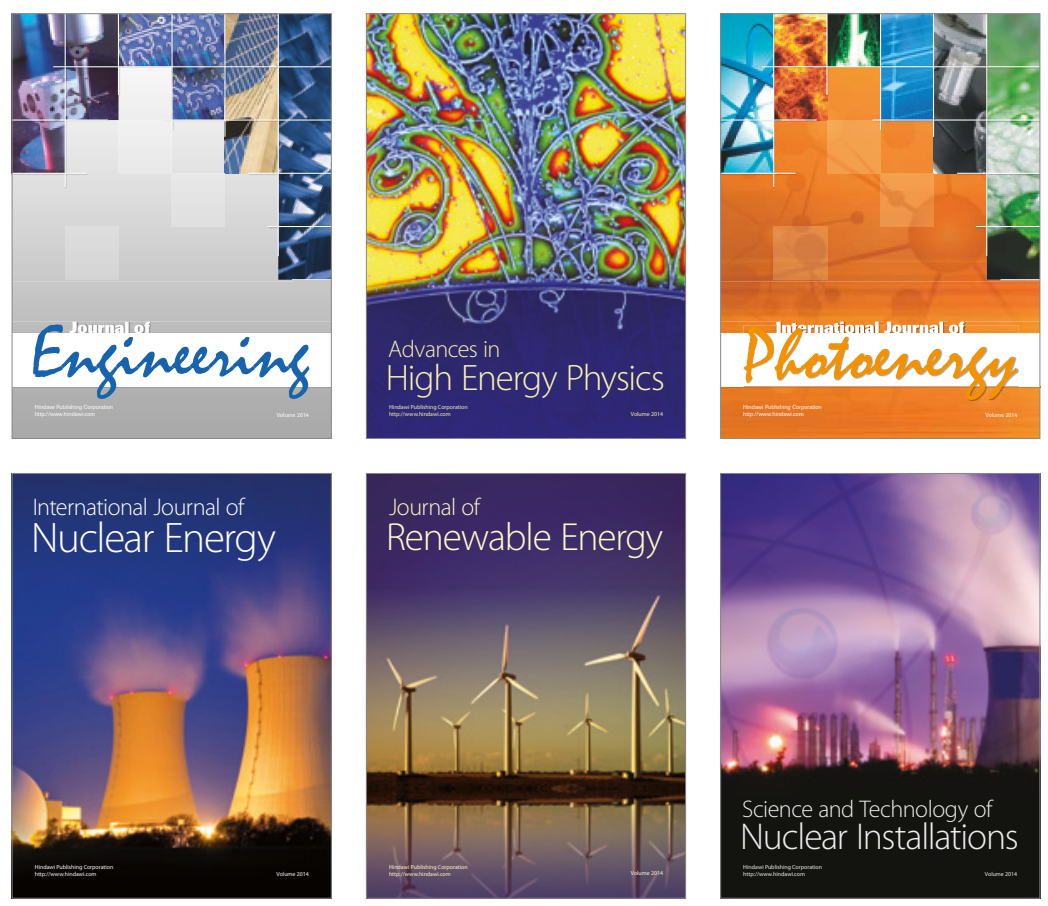

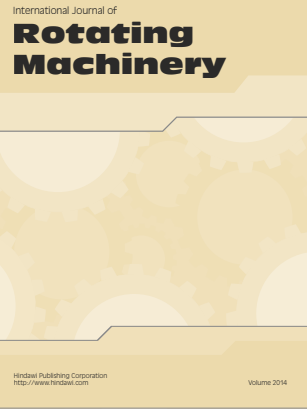

Journal of

Petroleum Engineering

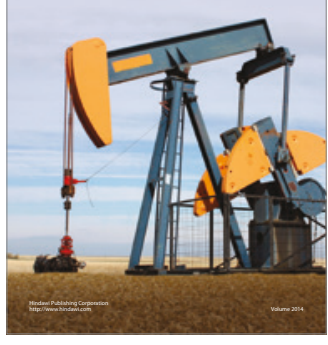

Journal of
Solar Energy
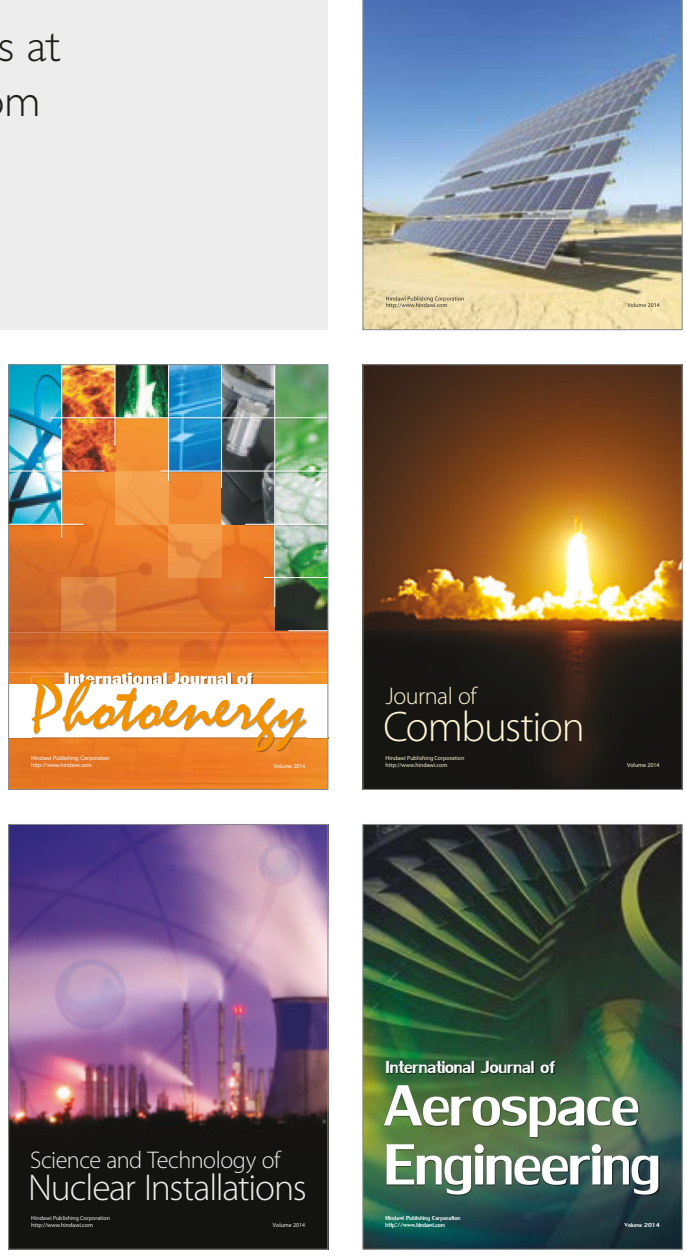